\title{
Understanding the effects of materiality on mental health
}

\author{
Lambros Malafouris (1)
}

BJPsych Bulletin (2019) 43, 195-200, doi:10.1192/bjb.2019.7

Keble College and the Institute of Archaeology, University of Oxford

Correspondence to Lambros Malafouris (lambros.malafouris@keble.ox.ac.uk)

First received 15 May 2018, final revision 7 Dec 2018, accepted 21 Dec 2018

(c) The Author 2019. This is an Open Access article, distributed under the terms of the Creative Commons Attribution-NonCommercial-

NoDerivatives licence (http:// creativecommons.org/licenses/by-ncnd/4.0/), which permits non-

commercial re-use, distribution, and reproduction in any medium, provided the original work is unaltered and is properly cited. The written permission of Cambridge University Press must be obtained for commercial re-use or in order to create a derivative work.
Summary Consensus is growing, in many areas of the humanities and social sciences, that aspects of the material world we live in have causal efficacy on our minds - the major dynamic being the plasticity of the brain linked to the affordances of our bodily engagements with things. The implications of that on how we approach and understand important mental health issues have not been adequately addressed. This paper proposes a material engagement approach to the study of the processes by which different forms of materiality achieve their effects. Focusing on the example of dementia, I propose that a collaboration between archaeology, anthropology, philosophy and psychiatry could help us to fill this gap in our knowledge, allowing us to understand the exact effects of everyday objects, personal possessions and forms of material engagement on people with dementia.

Declaration of interest None.

Keywords Things; dementia; anthropology; material engagement; archaeology.

\section{Bringing things to mind}

Human mental life is profoundly situated. The human mind, for better or worse, has always been inextricably intertwined with the plasticity (or stability) of our changing sociomaterial environments. This process of metaplasticity applies to human ontogeny as it does to human evolution. ${ }^{1-3}$ Different academic disciplines, constrained by the theoretical assumptions, the time scales and the analytical units that they use, are able to observe, and would probably emphasise, different aspects of the relationship between mind and matter. Still, the underlying message is the same: our everyday material habits and forms of material engagement (past, present and future) are inextricably linked with our cognitive and emotional lives - the major dynamic being the plasticity of the brain linked to the affordances of our body and the action possibilities offered by the things we make and use. We cannot understand human intelligence (cognition and affect) in isolation from its changing material and social surroundings. Material things matter and need to be taken seriously. ${ }^{4,5}$

This realisation of the interrelatedness between human experience, affect and materiality has, potentially, major implications for how we approach and understand important issues of mental health. Yet, those implications are not well understood. The important question concerning the influence of materiality on mental health and human well-being has not been adequately addressed and requires work across disciplinary boundaries. Although the agency of things ${ }^{6-8}$ and the vitality of matter ${ }^{9}$ have been central themes of research in the humanities and the social sciences, research in neuropsychiatry has, by and large, side-tracked the thorny issue of material engagement. Given what we now know about the importance of materiality in human social and cognitive life, ${ }^{10-12}$ this form of epistemic neglect is unacceptable and needs to be overcome. I do not wish, and there is no space in this brief editorial, to discuss the reasons for that blind spot. Instead, I want to suggest a way forward. Suffice it to say that the main reason psychiatry avoided investigating (at least in a direct and systematic sense) the full variation of the interactions between cognition and material culture, and their effects on mental health, is not because it sees those interactions as unimportant or uninteresting. Rather, it is because some traditional assumptions about the mind (for instance, the view that anything mental must refer to, and is explained by, processes internal to the individual) make it hard to study them. ${ }^{13,14}$ Those assumptions are changing, replaced by the more productive idea that the boundaries of the mind 'should not be set a priori, but should be responsive to the nature of the phenomena under study. ${ }^{15}$ The boundaries of the human mind have always been a problem, but perhaps never so problematic as they are today. ${ }^{16-20}$

There is unrealised potential here for creating new approaches to care and intervention that can complement existing practices and broaden, or in some cases challenge, prevailing assumptions in mental health. However, in 
order for this potential to be realised, a more nuanced, casespecific and evidence-based understanding of the material dimensions of human mental health is needed. ${ }^{21}$ How can we measure the effects that different material ecologies, ${ }^{12}$ practices and technologies have on human mental life? What constitutes evidence in that context? How can we best interpret existing evidence and use it to effect changes that could help improve our emotional and mental wellbeing? Largely, we still lack effective ways of answering those questions. Combined expertise and a range of specialisations are needed to develop both the theoretical and practical means that will allow us to make progress with these challenging issues.

\section{The material engagement approach}

The aim of this essay is to propose one possible path to this end, a path that could lead to better integration of in-depth anthropological and philosophical qualitative analysis with the quantitative methods and measures of psychiatry and neurophysiology. Specifically, I propose a material engagement approach combining methods from anthropology and embodied cognitive science that allows us to observe, to record and to compare the actual processes by which different materials and forms of material culture affect the people who experience and use them. ${ }^{22-24}$ The material engagement approach provides a theoretical framework tailored to facilitate a heightened responsiveness to the details of situated action and the affordance of the materials involved (the concept of affordance stems from Gibsonian ecological psychology, where it denotes the relational opportunities for perception and action between an organism and its environment). ${ }^{25,26}$ The distinctive feature of the material engagement approach is the commitment to a view of thinking as a process that is distributed, enacted and situated, as well as assembled, from a variety of non-localisable mental resources spanning the boundaries of the individual brain and body. Material engagement theory as an explanatory path is based on three interrelated working hypotheses, which can be summarised as follows. ${ }^{22-24}$ (a) The hypothesis of extended mind, which explores the constitutive intertwining of cognition with material culture; (b) the hypothesis of enactive signification, which explores the nature of the material sign not as a representational mechanism but as a semiotic conflation and cohabitation through matter that enacts and brings forth the world; and, finally, (c) the hypothesis of material agency, which explores agency not as a human property but as the emergent product of situated activity (Fig. 1).

Taken together, these hypotheses enable us to restate the problem of cognitive boundaries, offering a crossdisciplinary relational basis for understanding the material ecology of mental health that integrates the 'materiality turn' in humanities ${ }^{27}$ and social sciences with new embodied and enactive trends in philosophy and cognitive science. ${ }^{28}$ Traditional anthropological participant-observation combined with visual methods (e.g. photography/video capture and elicitation) and object interviews can be used for the study of everyday naturally occurring situated material activities and somatic modes of attention. ${ }^{29,30}$ The creative

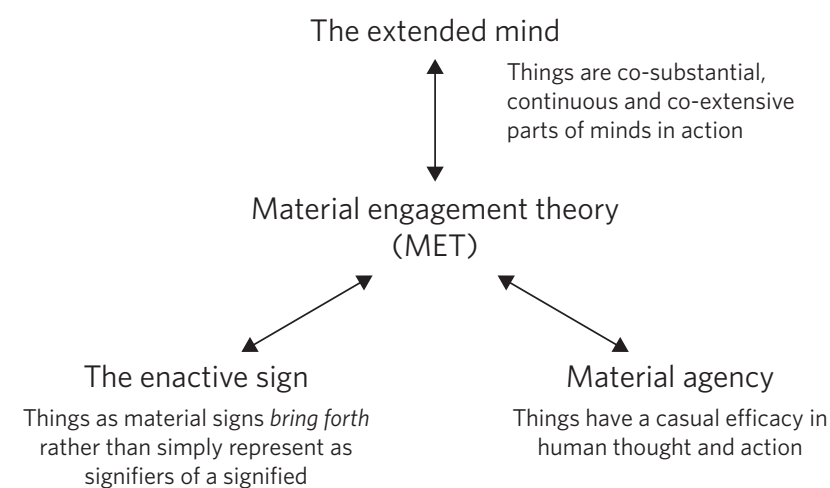

Fig. 1 Material engagement theory.

methods of art and medical humanities are also needed to investigate how different forms of material engagement achieve their effects. ${ }^{31-33}$ Some of the key issues include: (a) the role of arts and creative industries in psychotherapy; ${ }^{33,34}$ (b) the development of evidence-based understandings of the therapeutic effects and qualities of different art materials and digital media; (c) the role of museums in mental health ${ }^{35-38}$ as a space for creative interventions; and (d) the cross-cultural, ${ }^{39}$ social and gender ${ }^{40}$ dimensions of mental health.

Such a cross-disciplinary anthropological understanding will allow us to harness the power of creative industries more effectively and to develop new tools that will not just meet current needs but also help to generate new ideas on how to design a landscape of creative affordances for future experimentation. There is currently a lot of emphasis on the ways technological innovation (e.g. digital media, internet of things, big data, self-tracking) can be fostered to benefit older people. ${ }^{41-43}$ Still, there has been very little work trying to understand how these new innovations fit or compare with more traditional material ecologies and creative habits. ${ }^{44}$ Doing so could prove beneficial for all stakeholders involved.

To illustrate those claims, I will focus on the example of dementia.

\section{The case of dementia}

Dementia is one of the biggest mental health challenges modern society faces. ${ }^{45}$ The profound changes in people's lives brought about by dementia and by long-term caregiving are well known. This process of self-transformation is often described as a diminishment of or loss of self. ${ }^{46,47}$ All people who live with dementia (patients and family/carers) are affected. It is common to see dementia solely as the product of brain pathology and to leave people's bodily interactions with the material world unattended. But perhaps it is also important to pay closer attention and try to understand better how dementia extends beyond the brain of the individual. $^{20}$ The gradual loss of self is not solely the product of neurological factors. An impoverished material environment and the gradual loss of connection with significant others (humans and things) that provide a familiar, stable and comforting self-referential space also contribute to a diminishing 
capacity for memory, interaction and communication. One important question in this regard concerns how the evocative nature of material culture and its various cognitive, emotional and affective dimensions can be harnessed to guide the design of new care strategies and material settings that promote patients' agency, autonomy and ability in social interaction and communication. Are there ways to alter the person's material environment that can result in positive changes in embodied self-conceptualisation? ${ }^{48,49}$

One way to answer that question could be by examining the changes in materiality experienced during periods of major transition, for instance, during the transition from home to 'care home'. This is a challenging period, often marked by uncertainty, anxiety, confusion and distress, which can be explained in terms of changing cognitive ecology and the stripping away of personal possessions that help to constitute one's personal memories and self-identity. ${ }^{50}$ The philosopher Daniel Dennett, in his book Kinds of Minds (1996), describes this cognitive impairment when elderly people are in hospital, bereft of the usual contextual cues and affordances of their familiar home environments. ${ }^{51}$ More recently, Shaun Gallagher, ${ }^{26}$ adopting an enactive perspective, proposes an affordance-based approach to therapy that places special focus on the changing physical, social and cultural environments. He argues that a variety of mental health problems and neurological and psychiatric disorders can be understood in terms of changes in a subject's 'affordance space' - which is the lived space defined relative to the capacities (sensorimotor, social, cultural, cognitive) of a specific agent.

Significant objects and personal possessions that have been acquired and accumulated over the life course constitute material memories and material anchors of selfidentity. The powerful affective linkage of material possessions to one's identity explains the positive association between memorabilia and mood, as well as their observed influence on how elderly individuals achieve a sense of continuity. To lose these objects, often abruptly and unwillingly, owing to changes in residential circumstances, such as the transition from independent living to a nursing home, can be a 'major cause of loss and grieving for elders'. ${ }^{52}$ Understanding the cognitive life of things and the importance of object memories can allow us to develop strategies of care for the things that can actively enhance or even create a sense of continuity, stability, and comfort, especially during those transitional stages when one moves from home to a long-term care facility. ${ }^{53}$

Interestingly, in many care homes and hospices nowadays, residents are allowed to bring their own furniture and personal objects. One could track what they choose to take with them and how they actually use it. ${ }^{54}$ Are there any preferred types of objects? Do the objects carried along retain their original meaning and usage or do they become something different? Do individuals always keep what they want to remember? Do they always remember what they keep? What is the evidence that personal objects can facilitate patients' transition to their new and often alienating surroundings (e.g. providing cognitive and emotional support)? Can we provide informed guidance on how objects can be used more efficiently and appropriately in personal memory practices? There have been a number of studies looking at how old people moving into long-term care engage with their new material surroundings, ${ }^{55}$ but few of them have focused specifically on how dementia and other cognitive impairments may affect residents' ability to think and to feel with, through and about things. For instance, Buse and Twigg explored the potential of material objects to evoke narratives and elicit memories through the sensory and material dimensions of dress. The study focused on three main dimensions, i.e., kept clothes, discarded clothes and absent clothes, and used ethnographic methods to explore everyday experiences of clothing and their influence on maintenance of personal identity and biographical continuity. The study nicely illustrates the significance of dress, often unnoticed, in supporting personal identity in dementia care. $^{56,57}$

Combining traditional anthropological methods of participant observation with in-depth phenomenological analysis could help to answer questions of how different people experience this radical shift in their material ecology. Ethnographic attention to patients' changing bodily engagements, habits and material attachments during their transition to institutional care could provide a thorough first-hand examination of that. Cognitive ${ }^{58}$ and visual ethnography ${ }^{59}$ offer particularly apt methods to record and analyse everyday episodes of situated action and distributed intelligence, paying attention to the details of specific contexts. To investigate those processes, an analytical vocabulary cutting across brain-body-world divisions is required. Focusing primarily on non-verbal aspects of the dyadic or triadic interactions between patients, carers and things, one could analyse the sequential organisation of those interactions using a combination of pictures, written commentaries and graphic elements to illustrate features of material engagement such as movement, direction, eye-gaze, gesture, attention and action coordination.

It is important to recognise that every person's experience of dementia is different. People with dementia have their own unique life histories and actively make meaning of their lives through their attachments to and interactions with specific places, objects and people. People should be encouraged to spend time with the objects of their attention, to observe closely and with all their senses, and to draw what they observed or find other ways to voice their opinion. $^{60,61}$

One could look specifically at self-narratives evoked and constructed through shared discussions of artefacts and objects. Also of interest is to explore, more specifically, the role of biographical objects as memory scaffolds and affective probes of autobiographical memory through their attachments to family histories and self-identity, offering perhaps a complementary pathway to non-verbal facilitation of communication, promotion of independence, and rediscovery of personal identity. Communication is one of the major problems in dementia care, and participatory ethnography offers an appropriate means of interaction. To study people with dementia, it is essential to give them a voice. Material engagement interventions facilitate and support complex interactions, offering alternative non-verbal avenues of expression and communication. People with dementia may understand, do and express with and through things far more than they can express with language. 
What would be important to clarify in this connection is the extent to which memory loss in dementia and other neurodegenerative diseases might be partially compensated by the use of selected biographically salient objects and material scaffolds for self-narrative and autobiographical memory. For instance, studies on bodily and object ownership have shown that owned objects can trigger a strong memory trace and are often treated as psychological extensions of self. ${ }^{62}$ One could explore the effects that such strong associations between self and owned objects may have in the context of dementia.

Another promising avenue of research could be to investigate the cognitive mechanisms activated when people with dementia think with and through things in an embodied, performative manner, and to compare them with the cognitive mechanisms activated when they think about things in the internalist representational manner. Understanding those processes is important, because whereas most forms of dementia seem to affect the latter capacities for thinking about the world (in the sense of abstract recollection, selfnarrative, communication and language use), the former enactive capacities remain largely intact and could be re-used and developed to compensate for the lost ones. For instance, memory interventions in the form of memory books, photo albums and so-called memory boxes have repeatedly demonstrated their effectiveness as external memory aids and powerful communicative means. ${ }^{63}$ The precise cognitive function of those external memory prompts and cues remains largely unknown, but it has been suggested that they work precisely because they do not require conscious cognitive effort in order to trigger retrieval of related semantic information from memory storage, effecting positive changes in the conversational behaviours of people with a wide range of severity of cognitive impairment. ${ }^{64}$ There is little doubt that things and material objects evoke and trigger memories through associations with important life experiences and events, although exactly how that happens and how best those forms of material memory should be described is less understood. Beyond the widely recognised memories of objects, we should be considering also the possibility of object memories. Objects embody memories in their forms, life histories and uses that can provide powerful media for recollection, selfexpression and self-identification. The mundane things we own constitute memories of our past, material traces available to be re-enacted through our bodily engagements with the material world. In that sense, things provide a durable network of material signification, transposable dispositions and bodily habits which can be harnessed to enhance cognitive abilities or compensate for memory loss when biological memory is damaged. Like a blind's person stick, mundane things and media can help people to re-orient and re-structure their cognitive landscape (neural and extraneural) in a variety of ways. ${ }^{65} \mathrm{~A}$ material engagement approach could help us to explore whether there are ways we could structure and adapt the material ecology of any given environment in order to create scaffolds, material anchors $^{66}$ and action affordances ${ }^{26,67}$ able to effect a more efficient utilisation of brain networks or stimulate the person's ability to recruit alternate brain networks that could enhance cognitive reserve. ${ }^{68} \mathrm{~A}$ broader but related question in this regard could be whether different forms of material engagement can dynamically influence and mediate the relationship between brain damage and its clinical outcome. Here, one could refer to similar findings on collective remembering and cognitive reserve in old couples. ${ }^{69}$

\section{Conclusion}

In this essay, taking the example of dementia, I sketched the outline of a material engagement approach to mental health. I proposed that a collaboration of archaeology, anthropology, philosophy and neuropsychiatry could help us understand how people with dementia are actually engaging with their local material environments and the effects that the latter has on people's agency, cognitive abilities and selfhood across the full dementia care pathway. Such a collaboration could also form the basis of a longitudinal mixed method exploratory investigation of the possibilities for action and interaction that different objects and forms of material culture provide for people with dementia in common everyday situations and in different care settings (their homes and residential care).

Ultimately, the objective is to broaden recognition of the material aspects of dementia. That is, understanding better the ways by which different forms of material engagement can help people with dementia to: (a) remember and/or forget; (b) enact, express their agency and preserve their selfidentity; and (c) communicate and interact with others, especially family members and care providers. Hopefully, this will stimulate further cross-disciplinary research and broader engagement with material culture studies, which, in the context of current dementia and mental health research, are often seen as marginal and of limited value (despite the success of well-established tradition in artbased and occupational therapies).

Achieving these aims requires concerted action from a wide variety of organisations, collaboration and cooperation from the public. This exchange between practitioners, researchers and the public would generate further awareness, promoting new evidence-based cross-disciplinary research on the role of creative practices and material culture in mental health. It could also create transferable insights into the influence of creative practices in mental rehabilitation and in psychotherapy that could be used as alternative/additional solutions to traditional treatments of mental illness across the life course. The benefits of the proposed material engagement approach could be broad, offering important insights and practical recommendations for the well-being and long-term care of the aging population, with dementia or not.

Understanding how different forms of material engagement affect people's cognitive abilities and selfhood across the full dementia care pathway would also lead to specific evidence-based recommendations for designing interventions, material scaffolds and assistive techniques that could help people maintain and improve their mental well-being. This could also inform and facilitate safe and responsible design of healing environments, offer suggestions on how their effects should be measured, and suggest policy changes to provide a mental healthcare environment fit for the future. 
Fostering deeper understanding of the ecology of mental health and developing simple interventions enabling people to improve their psychological well-being is increasingly important in today's environment, with mental health leaders seeking innovative and cost-effective ways to optimise the quality of care. Concerted action and cross-disciplinary research is required to ensure that all gaps in research are filled. Understanding how different forms of material engagement affect people's mental health presents us with such a challenge.

\section{Acknowledgements}

I thank Shaun Gallagher, Jonathan Cole and Frank Rohricht for their valuable feedback in formulating the ideas presented in this paper. The writing of this article was assisted by the John Templeton Foundation Grant, Self-Bound: The Making of Human Consciousness (ID 60652), and the European Research Council Consolidator Grant, HANDMADE (No 771997 European Union Horizon 2020) awarded to Lambros Malafouris.

\section{About the author}

Lambros Malafouris is a senior research fellow at Keble College and the Institute of Archaeology, University of Oxford, UK.

\section{References}

1 Malafouris L. The brain-artefact interface (BAI): a challenge for archaeology and cultural neuroscience. Soc Cogn Affect Neurosci 2010; 5: 264-73.

2 Malafouris L. Metaplasticity and the human becoming: principles of neuroarchaeology. J Anthropol Sci 2010; 88: 49-72.

3 Malafouris L. 'Neuroarchaeology': exploring the links between neural and cultural plasticity. Prog Brain Res 2009; 178: 251-9.

4 Latour B. Where are the missing masses? The sociology of a few mundane artefacts. In Shaping Technology/Building Society: Studies in Sociotechnical Change (eds WE Bijker, J Law). MIT Press, 1992.

5 Miller D (ed). Material Cultures: Why Some Things Matter. UCL Press, 1998.

6 Knappett C, Malafouris L. Material Agency: Towards a NonAnthropocentric Approach. Springer Science \& Business Media, 2008.

7 Verbeek PP. What Things Do: Philosophical Reflections on Technology, Agency, and Design. Penn State Press, 2005.

8 Hicks D, Beaudry MC. The Oxford Handbook of Material Culture Studies. OUP Oxford, 2010

9 Bennett J. Vibrant Matter: A Political Ecology of Things. Duke University Press, 2009. Henare A, Holbraad M, Wastell S (eds). Thinking Through Things: Theorising Artefacts Ethnographically. Routledge, 2007.

10 Malafouris L, Renfrew C. An introduction to the cognitive life of things: archaeology, material engagement and the extended mind. In The Cognitive Life of Things: Recasting the Boundaries of the Mind (eds L Malafouris, C Renfrew): 1-12. McDonald Institute for Archaeological Research, 2010.

11 Turkle S. Evocative Objects: Things we Think With. MIT Press, 2007

12 Ingold T. Toward an ecology of materials. Annu Rev Anthropol 2012; 41(1): 427-42

13 Röhricht F, Gallagher S, Geuter U, Hutto DD. Embodied cognition and body psychotherapy: the construction of new therapeutic environments. Sensoria: A J Mind Brain Cult 2014; 10: 11-20.

14 Fuchs T. Embodied cognitive neuroscience and its consequences for psychiatry. Poiesis Prax 2009; 6(3-4): 219-33.

15 Hutchins E. Enaction, imagination, and insight. In Enaction: Toward a New Paradigm for Cognitive Science: (eds J Stewart, O Gapenne, A Di Paolo) 425-50. MIT Press, 2010.
16 Varela FJ, Thompson E, Rosch E. The Embodied Mind: Cognitive Science and Human Experience. MIT Press, 1991.

17 Clark A. Being There: Putting Brain, Body, and World Together Again. MIT Press, 1998.

18 Hutto DD, Myin E. Radicalizing Enactivism: Basic Minds Without Content MIT Press, 2012

19 Gallagher S. Enactivist Interventions: Rethinking the Mind. Oxford University Press, 2017.

20 Fuchs T. Ecology of the Brain: The Phenomenology and Biology of the Embodied Mind. Oxford University Press, 2017.

21 Buse C, Martin D, Nettleton S. Conceptualising 'materialities of care': making visible mundane material culture in health and social care contexts. Sociol Health IIIn 2018; 40(2): 243-55.

22 Malafouris L. How Things Shape the Mind. MIT Press, 2013.

23 Malafouris L. Mind and material engagement. Phenom Cogn Sci 2019 18(1): 1-17.

24 Malafouris L. Bringing things to mind: 4Es and material engagement. In The Oxford Handbook of $4 E$ Cognition (eds A Newen, $L$ de Bruin, G Shaun): 755-71. Oxford University Press, 2018.

25 Gibson J. The Ecological Approach to Visual Perception. Houghton Mifflin, 1979.

26 Gallagher S. The therapeutic reconstruction of affordances. Res Philosophica 2018; 95(4): 719-36.

27 Fox N. Health sociology from post-structuralism to the new materialisms. Health 2016; 20(1): 62-74.

28 Newen A, De Bruin L, Gallagher S (eds). The Oxford Handbook of $4 E$ Cognition. Oxford University Press, 2018

29 Goodwin C. Action and embodiment within situated human interaction. JPrag 2000; 32: 1489-522.

30 Woodward S. Object interviews, material imaginings and 'unsettling' methods: interdisciplinary approaches to understanding materials and material culture. Qual Res 2015; 16(4): 359-74.

31 Van Lith T. Art therapy in mental health: a systematic review of approaches and practices. Arts Psychotherapy 2016; 47: 9-22.

32 Van Lith T, Schofield MJ, Fenner P. Identifying the evidence-base for art-based practices and their potential benefit for mental health recovery: a critical review. Disabil Rehabil 2013; 35(16): 1309-23.

33 Beard R. Art therapies and dementia care: a systematic review. Dementia 2012; 11(5): 633-56.

34 Cousins E, Tischler V, Garabedian C, Dening T. Principles and features to define and describe arts interventions for people with dementia: a qualitative realist study. Arts Health 2018: 1-17.

35 Thomson LJ, Lockyer B, Camic PM, Chatterjee HJ. Effects of a museumbased social prescription intervention on quantitative measures of psychological wellbeing in older adults. Perspect Public Health 2018; 138(1): 28-38.

36 Thomson LJ, Ander EE, Menon U, Lanceley A, Chatterjee HJ. Evaluating the therapeutic effects of museum object handling with hospital patients: a review and initial trial of well-being measures. J Appl Arts Health 2011; 2(1): 37-56.

37 Chatterjee H, Noble G. Museums, Health and Well-Being. Routledge 2013.

38 Mangione $\mathrm{G}$. The art and nature of health: a study of therapeutic practice in museums. Sociol Health IIIn 2018; 40(2): 283-96.

39 Mackenzie J, Bartlett R, Downs M. Moving towards culturally competent dementia care: have we been barking up the wrong tree? Rev Clin Gerontol 2015; 15(1): 39-46.

40 Bartlett R, Gjernes T, Lotherington AT, Obstefelder A. Gender, citizenship and dementia care: a scoping review of studies to inform policy and future research. Health Soc Care Commun 2018; 26(1) 14-26.

41 Gillespie A, Best C, O'Neill B. Cognitive function and assistive technology for cognition: a systematic review. J Int Neuropsychol Soc 2012 18(1): 1-19. 
42 Jamieson M, Cullen B, McGee-Lennon M, Brewster S, Evans JJ. The efficacy of cognitive prosthetic technology for people with memory impairments: a systematic review and meta-analysis. Neuropsychol Rehabil 2014; 24(3-4): 419-44.

43 Lorenz K, Freddolino PP, Comas-Herrera A, Knapp M, Damant J. Technology-based tools and services for people with dementia and carers: mapping technology onto the dementia care pathway. Dementia 2019; 18(2): 725-41.

44 Buse C, Martin D, Nettleton S. Conceptualising 'materialities of care': making visible mundane material culture in health and social care contexts. Sociol Health IIIn 2018; 40(2): 243-55.

45 Livingston G, Sommerlad A, Orgeta V, Costafreda SG, Huntley J, Ames $D$, et al. Dementia prevention, intervention, and care. Lancet 2017; 390 (10113): 2673-734.

46 Kontos PC. Ethnographic reflections on selfhood, embodiment and Alzheimer's disease. Ageing Soc 2004; 24: 829-49.

47 Caddell LS, Clare L. I'm still the same person: the impact of early-stage dementia on identity. Dementia 2011; 10(3): 379-98.

48 Buse C, Twigg J. Materialising memories: exploring the stories of people with dementia through dress. Ageing Soc 2016; 36(6): 1115-35.

49 Yatczak J. Everyday material engagement: supporting self and personhood in people with Alzheimer's disease. Phenom Cogn Sci 2018: 1-18.

50 Phenice LA, Griffore RJ. The importance of object memories for older adults. Educ Gerontol 2013; 39(10): 741-9.

51 Dennett D.C., Kinds of Minds: 138-9. Basic Books, 1996.

52 Phenice LA, Griffore RJ. The importance of object memories for older adults. Educ Gerontol 2013; 39(10): 742.

53 Wapner S, Demick J, Redondo JP. Cherished possessions and adaptation of older people to nursing homes. Int J Aging Hum Dev 1990; 31: 219-35.

54 Lovatt M. Becoming at home in residential care for older people: a material culture perspective. Sociol Health IIIn 2018; 40(2): 366-78.

55 Cipriani J, Kreider M, Sapulak K, Jacobson M, Skrypski M, Sprau K. Understanding object attachment and meaning for nursing home residents: an exploratory study, including implications for occupational therapy. Phys Occup Ther Geriatr 2019; 27(6): 405-22.
56 Buse C, Twigg J. Materialising memories: exploring the stories of people with dementia through dress. Ageing Soc 2016; 36(6): 1115-35.

57 Phillipson L, Hammond A. More than talking: a scoping review of innovative approaches to qualitative research involving people with dementia. Sociol Health IIIn 2018; 17(1): 1609406918782784.

58 Hutchins E. Cognitive ecology. Top Cogn Sci 2010; 2(4): 705-15.

59 Banks M, Zeitlyn D. Visual Methods in Social Research (2nd edn.). Sage, 2015.

60 Bartlett R. Modifying the diary interview method to research the lives of people with dementia. Qual Health Res 2012; 22(12): 1717-26.

61 Woodward S. Object interviews, material imaginings and 'unsettling' methods: interdisciplinary approaches to understanding materials and material culture. Qual Res 2015; 16(4): 359-74.

62 Cunningham SJ, Turk DJ, Macdonald LM, Macrae CN. Yours or mine? Ownership and memory. Conscious Cogn 2008; 17: 312-8.

63 Caddell LS, Clare L. Interventions supporting self and identity in people with dementia: a systematic review. Aging Ment Health 2011; 15(7): 797-810.

64 Bourgeois MS, Camp C, Rose M, White B, Malone M, Carr J, et al. A comparison of training strategies to enhance use of external aids by persons with dementia. J Commun Disord 2003; 36: 361-78.

65 Malafouris L, Koukouti MD. How the body remembers its skills: memory and material engagement. J Conscious Stud 2018; 25(7-8): 158-80.

66 Hutchins E. Material anchors for conceptual blends. J Pragmat 2005; 37: 1555-77.

67 Rietveld E, Kiverstein J. A rich landscape of affordances. Ecol Psychol 2014; 26: 325-52.

68 Stern $Y$. What is cognitive reserve? Theory and research application of the reserve concept. J Int Neuropsychol Soc 2002; 8: 448-60.

69 Harris CB, Barnier AJ, Sutton J, Keil PG. Couples as socially distributed cognitive systems: remembering in everyday social and material contexts. Memory Stud 2014; 7: 285-97.

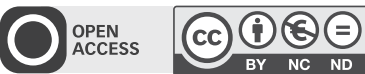

